\title{
Émile Verhaeren, Les Flamandes et Les Moines (Poésie complète, 5)
}

\section{Angélique Gigan}

\section{(2) OpenEdition}

1 Journals

\section{Édition électronique}

URL : http://journals.openedition.org/studifrancesi/6403

DOI : ERREUR PDO dans /localdata/www-bin/Core/Core/Db/Db.class.php L.34 : SQLSTATE[HY000]

[2006] MySQL server has gone away

ISSN : 2427-5856

\section{Éditeur}

Rosenberg \& Sellier

\section{Édition imprimée}

Date de publication : 1 novembre 2010

Pagination : $581-582$

ISSN : 0039-2944

\section{Référence électronique}

Angélique Gigan, «Émile Verhaeren, Les Flamandes et Les Moines (Poésie complète, 5) 》, Studi Francesi [En ligne], 162 (LIV | III) | 2010, mis en ligne le 30 novembre 2015, consulté le 07 janvier 2021. URL : http://journals.openedition.org/studifrancesi/6403 ; DOI : https://doi.org/ERREUR PDO dans / localdata/www-bin/Core/Core/Db/Db.class.php L.34 : SQLSTATE[HY000] [2006] MySQL server has gone away

Ce document a été généré automatiquement le 7 janvier 2021.

\section{(c) $(1)$}

Studi Francesi è distribuita con Licenza Creative Commons Attribuzione - Non commerciale - Non opere derivate 4.0 Internazionale. 


\title{
Émile Verhaeren, Les Flamandes et Les Moines (Poésie complète, 5)
}

\author{
Angélique Gigan
}

\section{RÉFÉRENCE}

ÉMILE VERHAEREN, Les Flamandes et Les Moines (Poésie complète, 5). Édition critique établie par Michel Otten. Bruxelles, Luc Pire/Archives et Musées de la Littérature, 2008, «Archives du futur», 2008, pp. 382.

1 Le cinquième tome de Poésie complète du poète belge Émile Verhaeren (1855-1916) édité par Michel Otten, regroupe ses deux premiers recueils, Les Flamandes (1883) et Les Moines (1885). L'ouvrage s'ouvre sur une introduction de Véronique JAGO-ANTOINE, qui situe ainsi une œuvre dont le rapport entre art pictural et poésie est manifeste. Ainsi, l'insertion d'illustrations de tableaux de peintres tels que Pierre-Paul Rubens, Jan Steen ou Constantin Meunier, etc., nous transporte d'emblée dans l'univers verhaerien, partagé ici entre le monde festif des Flamandes et l'atmosphère ascétique des Moines.

2 L'édition des textes est claire et minutieuse: la disposition sur une double page, préférable aux notes infrapaginales, facilite la lecture présentant à droite la dernière version du poème publiée du vivant de l'auteur et à gauche les variantes des vers. Les appendices viennent enrichir l'ensemble grâce à l'ajout de poèmes supprimés par Verhaeren lors du remaniement de ses recueils. Il manquerait toutefois des éléments d'ordre biographique, notamment une chronologie synoptique qui aurait permis de situer Les Flamandes et Les Moines dans la vie de Verhaeren.

3 La présence de ces deux recueils dans un même volume n'obéit pas seulement à un principe chronologique qui vise à rassembler les deux premières œuvres du poète, elle est aussi thématique. S'il est vrai que le titre de chacun de ses recueils oppose d'emblée un monde de réjouissances charnelles à dominante féminine (La Vachère, Art flamand, Kato, Cuisson du pain, La Grande Chambre, Truandailles, Aux Flamandes d'autrefois) à la 
sobriété monacale, il n'en demeure pas moins qu'il existe une continuité certaine entre les deux œuvres.

4 Les références à l'art pictural, comme l'indique notamment le poème initial des Flamandes, «Les Vieux Maîtres», sont bien plus que de simples allusions ou renvois à des modèles établis. Verhaeren s'inscrit dans une lignée esthétique, transposant cet héritage artistique dans ses poèmes. Si les liens entre peinture et poésie sont patents avec un intitulé tel que Les Flamandes, les poèmes composant Les Moines mettent également en relief ce rapport entre image et texte: «Une Estampe» et «Croquis de cloître», qui apparaît dans quatre versions différentes auxquelles s'ajoutent deux autres présentées en appendice, relèvent ainsi du vocabulaire pittoresque.

5 Mais l'importance de l'héritage pictural ne se limite pas uniquement à l'emploi de termes propres à ce domaine. Il caractérise surtout le style d'Émile Verhaeren qui opte volontiers pour une poésie descriptive, une poésie qui donne à voir. Les titres sont une nouvelle fois révélateurs à cet égard: certains poèmes sont consacrés tantôt à la description de paysages, c'est le cas notamment dans les Flamandes («Les Plaines», «La Ferme», «L'Enclos», «Les Granges», etc.), tantôt à celle de personnages («Moine épique», «Moine doux», «l'Hérésiarque», «Moine simple», etc.). Les animaux de la ferme font eux aussi l'objet de tableaux poétiques («Les Porcs», «La Vache»). Néanmoins, ce sont les descriptions liées à la temporalité qui dominent. Ainsi, dans Les Moines, les moments de la journée sont merveilleusement dépeints («Soir religieux», «Les Matines», «Les Vêpres», etc.), tandis que dans Les Flamandes les différents aspects de la vie paysanne sont magnifiquement mis en vers («Les Paysans», «Les Gueux», «Truandailles», etc.). Les événements donnent lieu également à de très beaux poèmes dans les deux recueils, notamment ceux qui ont pour thème la mort («Les Funérailles», «Agonie de moine», «Mort chrétienne», «Le Cimetière»).

6 En somme, ces premières œuvres de Verhaeren sont comme des esquisses qui dessinent les grandes lignes de son art poétique où la frontière entre peinture et poésie vise à s'estomper (de ce point de vue, les illustrations incluses dans l'introduction font véritablement sens) et annonce un poète génial. Nul doute que ce cinquième tome de Poésie complète permet de redécouvrir Verhaeren et que la lecture charnelle des Flamandes et celle plus spirituelle des Moines sont un voyage imaginaire dont on revient émerveillé.

7 L'entreprise éditoriale menée par Michel Otten est sans conteste salutaire, contribuant à valoriser l'œuvre verhaerienne dans un beau volume où le jeu des couleurs met en lumière la grandeur du monde paysan et de l'univers monacal. 